\title{
Anomaly, Jonathan (2020), Creating Future People: The Ethics of Genetic Enhancement, New York \& London: Routledge, 126 pp., ISBN 978-0-367-20312-2
}

Genetic technologies are progressing at a fast rate and offer many possibilities, but also raise many ethical dilemmas-especially when it comes to human genetic enhancement. While current possibilities in this regard are still limited, it is important to consider the benefits and risks of enhancement soon enough, in order to be ready to act responsibly once the relevant technologies are available. Two dangers should be kept in mind: the misuse of technologies and, less obviously, the risk of humans being overwhelmed by their moral intuitions.

Jonathan Anomaly may be the ideal man to tackle such a subject: an associate director and lecturer at the PPE Program (philosophy, politics, and economics) of the University of Pennsylvania, he has proven himself to be independentminded and wary of conformism and intolerance in academe (see his articles for Quillette, https://quillette.com/author/jonny-anomaly/). In Creating Future People, he addresses the benefits and risks of enhancing traits such as intelligence, morality, beauty, and health.

The book requires basic knowledge in genetics (e.g., what DNA is) but is still accessible to a wide educated public. After a short preface introducing the implications of recent technological innovations (pp. vii-xiii), and after a very brief (and interesting) acknowledgments section (pp. xiv-xv), the author directly delves into the question of what is permissible and what is not.

The possibility of enhancing intelligence is quite frequently evoked due to the important social implications of this trait, and this may be one of the reasons why Anomaly dedicates his first chapter to it (pp. 1-18). He writes a few pages on what intelligence is and why it matters (pp. 2-6), a reasonable choice given the persistence of numerous misconceptions about this trait. The chapter on intelligence is the only one to provide such basic information. The other topics Anomaly discusses are morality or goodness (Chapter 2), beauty (Chapter 3), and immunity (Chapter 4). His Chapter 5 addresses not only the possibility of creating synthetic people but also, more generally, the numerous personal responsibilities and ethical dilemmas that will come with the development of enhancing technologies.

Anomaly's discussion of the pros and cons of enhancement has two major strengths: firstly, despite the brevity of his book, he pays important attention 
to issues that one may not think about immediately, e.g., possible conflicts between individual benefits and the common good. Take, for instance, genetic engineering of the immune system:

If each parent chooses embryos that make it more likely that their children have genes that confer immunity to particular microbes that threaten the local environment, they might inadvertently create immune-monocultures that make it easier for mutated microbes to decimate populations (p. 57).

Secondly, being aware that his readers may embrace a wide variety of worldviews, Anomaly points out that there are many principles on which we disagree, but also "often a surprising agreement about which values are at stake" (p. 10). Therefore, he offers two ethical principles that most of his readers will agree with: procreative beneficence, i.e., the duty to bring to life children with the best possible chances, and procreative altruism, i.e., the duty to bring to life children who are most likely to contribute to the welfare of others (see pp. $\mathrm{x}$-xii)

Anomaly is aware that those who write on the topic of human enhancement need to address past abuses committed in the name of enhancement. He points out that the rise of Galton's eugenics movement owes much to late nineteenthcentury concerns about upper-class families, held to have higher intelligence and impulse control, having less children than lower-class families (p. 80). After quoting Darwin and Schrödinger, Anomaly writes that this phenomenon (generally know as dysgenics, a term Anomaly does not use in Creating Future People) has continued and that we should all be concerned: "The demographic consequences of these facts are rarely discussed, but if these patterns continue, it's hard to see them as being good for future people unless genetic enhancement technologies become viable and widely used" (p. 79).

Perhaps most unconventionally, Anomaly rejects the view that the Holocaust was eugenically motivated:

Many authors describe the Holocaust as part of the German eugenics program. But this is misleading. First, Hitler complained of Jews as 'dominating' the sciences, journalism, medicine, law, and finance. So he certainly didn't think of them as 'inferior' in the sense of lacking many of the traits the German eugenics were supposed to encourage (Anomaly, 2020, p. 86, n. 2).

While Anomaly's point is sound, his case would have been stronger had he added references to other publications dealing with this issue, e.g., books by Seymour W. Itzkoff. 
Anomaly's discussion of intelligence is another example of his capacity to take into account many possible objections, and to highlight elements that are important but far from obvious. He admits that enhancing intelligence might be risky insofar as smart people are more effective at destroying others; however, he notes that the risk can be reduced with the help of moral enhancement, that smarter people tend to create more prosperous and stable societies, and that it is in any case futile to ban cognitive enhancement technology, since "the richest, smartest, and most powerful people would likely find a way to access black markets for cognitive enhancement" (p. 8).

In addition, Anomaly extensively deals with the question of inequality. $\mathrm{He}$ points out that intelligence and other beneficial traits may constitute positional goods: their value depends on how much of it other people have, and the use of enhancement technologies by some may make the competence of others less economically valuable (pp. 11-13). Another danger is that intellectual inequality may widen so much that some people would eventually be seen as having a higher moral status than others (pp. 13-17). However, Anomaly wisely points out that, if an opponent of enhancement evokes the risk of exacerbating inequalities, this argument can be turned around: genetic disparities already exist, and "if inequalities are likely to increase when some choose to genetically enhance their children and some don't, this may be a reason for everyone to enhance rather than for everyone to refrain" (p. 52). Anomaly also notes that at a later stage, once genetic enhancement technologies are sufficiently reliable (i.e., all changes are reversible and off-target mutations can be avoided; see p. 65), the refusal to use these technologies may be seen as criminal neglect: "Refraining from a safe and beneficial genetic enhancement may be on a par with parents refusing to allow their children to be vaccinated against an infectious disease simply because not everyone in the world has the same opportunities" (p. 52). Finally, Anomaly points out that the measures adopted will greatly depend on the type of governments in place, and on the way people are informed and react to information about genetics.

Overall, Anomaly has a sober tone and gives an impression of integrity and humility. Perhaps the most revealing passages are found in the acknowledgments section: he thanks his parents "for supporting career moves that decreased my income but increased my freedom to explore ideas" (p. xiv), and his mentor Jerry Gaus for encouraging him "to read widely, and to avoid chasing prestige rather than truth" (p. xv). 
Julien Delhez

Anomaly has produced an excellent little volume which argues that humanity should be in charge of its own destiny. It is primarily aimed at knowledgeable and intelligent readers, and there is little doubt that it will encourage them to ask themselves many new questions.

\section{Julien Delhez}

Seminar für Ägyptologie und Koptologie, Georg-August-Universität Göttingen 